\title{
Retraction Note: Cloud resources-based water and soil pollution control in mountainous areas and rural tourism landscape design
}

\author{
Bo Tan ${ }^{1} \cdot$ Zhenzhen Liü
}

Published online: 6 December 2021

(c) Saudi Society for Geosciences 2021

Retraction Note: Arabian Journal of Geosciences (2021)

14: 1500

https://doi.org/10.1007/s12517-021-07837-2

The Editor-in-Chief and the Publisher have retracted this article because the content of this article is nonsensical. The peer review process was not carried out in accordance with the Publisher's peer review policy. The authors have not responded to correspondence regarding this retraction.

The original article can be found online at https://doi.org/10.1007/ s12517-021-07837-2.

Bo Tan

277757316@163.com

1 Nanchong Vocational College of Culture and Tourism, Nanchong 637000, Sichuan, China

2 School of Management, Chongqing College of International Business and Economics, He'chuan 401520, Chongqing, China 